\title{
Neurogenic Coronary Vasoconstrictor Effects of Digitalis during Acute Global Ischemia in Dogs
}

\author{
Kiran B. Sagar, Eric C. Hanson, and William John Powell, JR., \\ Cardiac Unit and the Department of Medicine of the Massachusetts \\ General Hospital and Harvard Medical School, Boston, Massachusetts \\ 02114
}

A B S TRACT The rapid i.v. administration of digitalis has recently been shown to cause a substantial increase in coronary vascular resistance in the normal heart. This neurogenically mediated decrease in coronary blood flow would be potentially detrimental if it occurred during ischemia. The present study evaluates the effects of i.v. acetylstrophanthidin and digoxin on coronary vascular resistance during acute global ischemia in 29 dogs anesthetized with chloralose and urethane. Under these conditions, $0.5 \mathrm{mg}$ of i.v. acetylstrophanthidin in 15 dogs resulted in erratic increases in coronary vascular resistance. The peak rise was 12 $\pm 5 \%$ above control $(P<0.01)$. In 7 of the 15 dogs, the initial erratic rise in coronary vascular resistance culminated in a steep rise associated with acute elevation in left ventricular end-diastolic pressure, which in four dogs terminated in ventricular fibrillation. During the nonischemic control periods, the peak rise in coronary vascular resistance with acetylstrophanthidin was $16 \pm 1 \%$ above control $(P<0.01)$. In five dogs, prior alpha adrenergic receptor blockade with phenoxybenzamine prevented the rise in coronary vascular resistance with acetylstrophanthidin during ischemia.

Similar erratic increases in coronary vascular resistance were observed with i.v. digoxin ( $1 \mathrm{mg}$ ) during ischemia in three dogs. In two of these dogs, there was a progressive rise in coronary vascular resistance associated with elevation of left ventricular end-diastolic pressure and ventricular fibrillation. The increase in coronary vascular resistance with digoxin during ischemia was abolished with phenoxybenzamine in two additional dogs.

Thus, i.v. digitalis in the ischemic heart results in potentially detrimental increases in coronary vascular

During this study Dr. Sagar was the Paul Dudley White Fellow of the Massachusetts Affiliate of the American Heart Association.

Received for publication 13 December 1976 and in revised form 13 May 1977. resistance mediated through alpha adrenergic receptor stimulation.

\section{INTRODUCTION}

Recently, a neurogenic vasoconstrictor effect of digitalis has been demonstrated in the coronary circulation under nonischemic conditions $(1,2)$. However, it is not known if this neurogenic vasoconstriction occurs under conditions of myocardial ischemia, because various metabolic changes which result in vasodilation $(3,4)$ occur in the heart during ischemia. Since digitalis is frequently administered to patients with coronary artery disease, coronary vasoconstriction would produce potentially detrimental effects on an already compromised myocardium.

Balcon et al. (5) have demonstrated that soon after i.v. digitalization of patients with acute myocardial infarctions and left ventricular failure, there was a fall in cardiac output without any change in peripheral vascular resistance. Hodges et al. (6) noted a deterioration of ventricular function shortly after i.v. digitalization in 6 of 10 patients with acute myocardial infarctions and heart failure. Several other studies (7-9) have also raised the possibility that i.v. digitalis produces only detrimental hemodynamic effects in patients with acute cardiac ischemia.

Thus, the present study was designed to evaluate whether or not neurogenic coronary vasoconstrictor effects of digitalis are present during ischemia and to determine whether these effects, if documented, could be involved in a deterioration of cardiac function after i.v. digitalization.

\section{METHODS}

The experiments were performed in 29 mongrel dogs, each weighing $20-24 \mathrm{~kg}$. All dogs were anesthetized with i.v. chloralose $(60 \mathrm{mg} / \mathrm{kg}$ ) and urethane $(600 \mathrm{mg} / \mathrm{kg})$. After an induction of anesthesia, an endotracheal tube was inserted. The animals were ventilated with a Harvard positive-pressure res- 
pirator (Harvard Apparatus Co., Inc., Millis, Mass.) with a mixture of $95 \%$ oxygen and $5 \%$ carbon dioxide at a rate of $14-$ $18 \mathrm{cycle} / \mathrm{min}$. The blood from two or more donor dogs was used for each experiment. Donor dogs were anesthetized with i.v. sodium methohexital (Brevital, Eli Lilly and Company, Indianapolis, Ind.) and exsanguinated from the femoral artery. $50-100 \mathrm{~cm}^{3}$ of sodium bicarbonate $\left(44 \mathrm{meq} / 50 \mathrm{~cm}^{3}\right)$ and 20 $\mathrm{cm}^{3}$ of heparin $\left(1,000 \mathrm{U} / \mathrm{cm}^{3}\right)$ were added to the blood from donor dogs.

In the operative animals, a left thoracotomy was performed. Care was taken during surgery to prevent damage to the neural supply to the heart. Coronary sinus blood flow was measured by the method described by Gregg and Fisher (10). A wide-bore (Bardic no. 16) cannula (C. R. Bard, Inc., Murray Hill, N. J.) was inserted through the right atrial appendage and ligated in place in the most distal part of the coronary sinus. The cannula was held in a horizontal position by a brace $(1,2)$. This prevented motion that might lead to transient occlusion of some of the small venous tributaries emptying into the coronary sinus near the right atrium. The position of the cannula was noted at postmortem examination to ensure that there was no occlusion of these small tributaries. Coronary sinus outflow was measured by direct collection of venous blood in graduated cylinders. The coronary sinus effluent was returned to a reservoir to be oxygenated (Fig. 1).

In cannulating the left coronary artery, care was taken to avoid damage to the surrounding nerve plexus and to avoid stimulation of receptors in the wall. As depicted on the left of Fig. 2, a guide wire was introduced in retrograde fashion into one of the distal branches of the left anterior descending

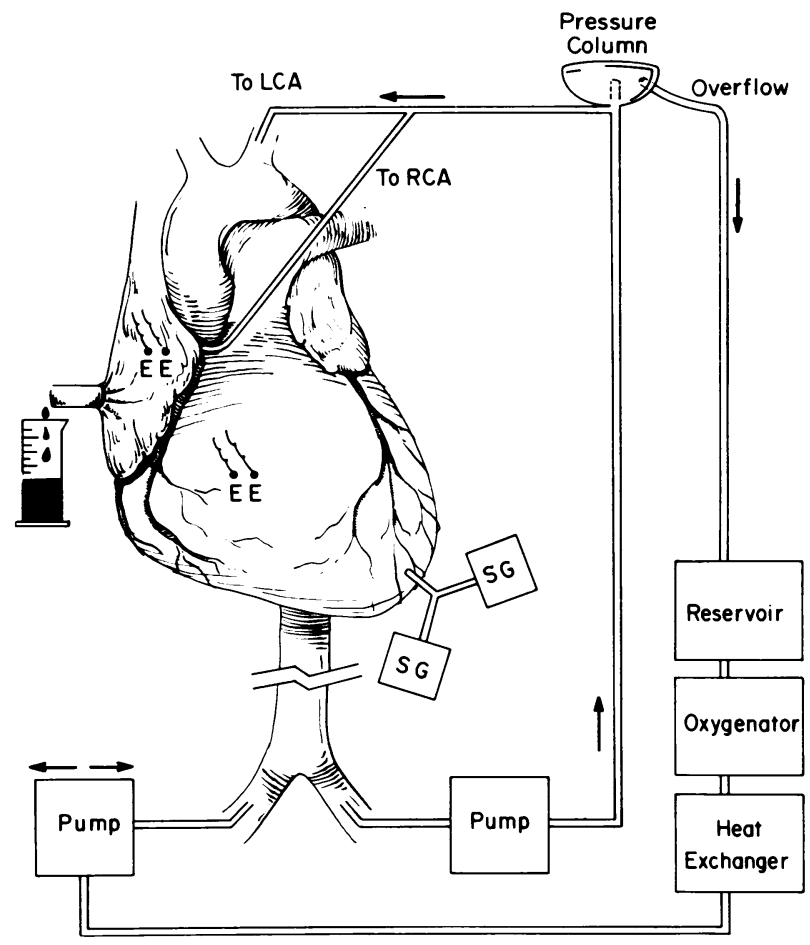

FIGURE 1 Schematic diagram of the canine preparation used for the experiments. The column which was used to control coronary artery perfusion pressure constant is shown on the right. SG, strain gauge; E, pacing electrode; LCA, left main coronary artery; RCA, right coronary artery. See text for details.

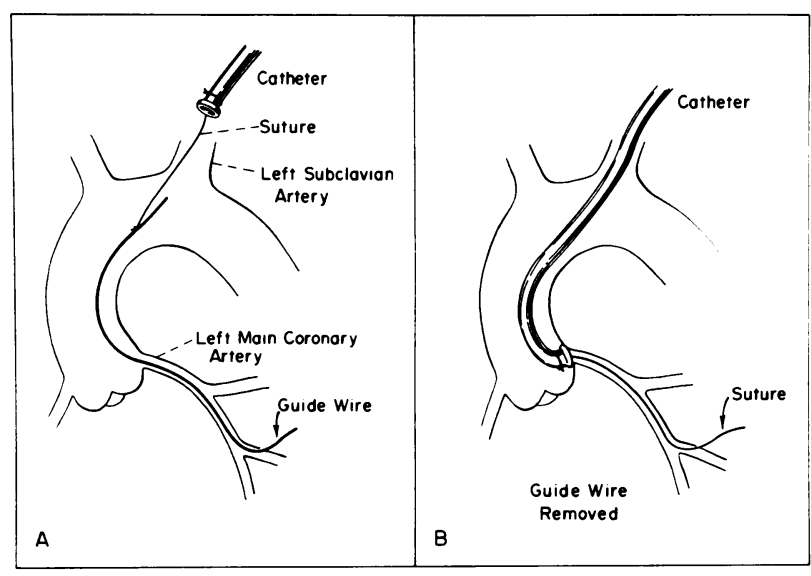

FIGURE 2 Schematic representation of the method used for perfusion of the left coronary artery. (A) Shows retrograde introduction of the guide wire into left subclavian artery. (B) Shows the cannula in place against the ostium of the left coronary artery.

artery, advanced proximally, and directed out through the left subclavian artery. An 0-silk suture was ligated to its proximal end. The other end of the suture was tied to a cannula (C. R. Bard, Inc.) with a donut-shaped sleeve (Fig. 2). The cannula was introduced into the aorta through the left subclavian artery. The guide wire and the suture carrying the cannula were then gently pulled out of the distal coronary artery until the donut-shaped sleeve approximated the orifice of the left main coronary artery (right panel of Fig. 2). The proximal right coronary artery was dissected free from surrounding structures, and a polythene perfusion cannula was inserted through an arteriotomy and ligated in place. Both coronary arteries were perfused from the femoral arterial system of the operative dog through an overflow column at constant pressure (Fig. 1). Global ischemia of the heart was produced by lowering the pressure column until the left ventricular end-diastolic pressure increased to the vicinity of $15 \mathrm{~cm}$ of water. The absence of a leak around the cannula perfusing the left coronary artery was confirmed by documenting the similarity of the pressure measured in the overflow column to that of a distal branch of the left coronary artery.

To maintain heart rate constant, the sinoatrial node was crushed and atrioventricular sequential pacing was employed at a rate of $150 / \mathrm{min}$ (model $5837 \mathrm{~A}-\mathrm{V}$ pulse generator, Medtronic, Inc., Minneapolis, Minn.). The interval between atrial and ventricular pacing was set $75 \mathrm{~ms}$ for all experiments. The arterial pressure was monitored and maintained constant throughout the experiment by pumping blood in and out of the femoral artery of the dog.

Left ventricular pressure and left ventricular diastolic pressure were measured via a short, rigid, wide-bore cannula placed through the apical dimple and sutured in place. All pressures were monitored with Statham P23Db pressure transducers (Statham Instruments Div., Gould Inc., Oxnard, Calif.). An electrocardiogram, systemic blood pressure, coronary artery pressure, full left ventricular pressure, left ventricular end-diastolic pressure, and the peak first derivative $(d \mathrm{p} / d \mathrm{t})$ of the full left ventricular pressure were recorded on a Hewlett Packard model 7700 oscillograph (Hewlett-Packard Co., Waltham Division, Waltham, Mass.). The frequency response of the pressure measurement system was linear up to $30 \mathrm{cycle} / \mathrm{s}$. The rate of rise of left ventricular pressure $(d \mathrm{p} / d \mathrm{t})$ was obtained by R.C. electronic differentiation of the full left 
ventricular pressure. Calibration of the $d \mathrm{p} / d \mathrm{t}$ differentiator was accomplished by supplying a waveform at known slope to the differentiating circuit, which has a time constant of $0.001 \mathrm{~s}$ and a cutoff at 160 cycle/s.

Coronary vascular resistance $(\mathrm{CVR})^{1}$ was calculated as the ratio of the mean coronary artery perfusion and coronary sinus blood flow. Changes in CVR were expressed as percent change from control.

In 10 animals receiving acetylstrophanthidin $(0.5 \mathrm{mg})$, coronary arterial and venous $\mathrm{pH}, \mathrm{PCO}_{2}, \mathrm{PO}_{2}$, potassium, and lactate were determined during nonischemic and ischemic periods. Arterial blood gases, electrolytes, and hematocrit were determined during each experiment and were within the physiologic limits.

Statistical analysis was obtained using Student's $t$ test, and results were considered significant when $P<0.05$.

Experimental procedure. In 11 dogs, when stability of the preparation had been documented by observation of the systemic hemodynamics and by 10 consecutive 1-min coronary sinus blood flow measurements, $0.5 \mathrm{mg}$ of acetylstrophanthidin was administered intravenously via the brachial vein under nonischemic conditions. After the injection, 1-min coronary sinus blood flow measurements were obtained for each of $30 \mathrm{~min}$. Tracings were obtained at paper speeds of 0.25 and 100 $\mathrm{mm} / \mathrm{s}$ during the time of each experiment. An increase in CVR during the nonischemic control period after acetylstrophanthidin administration indicated that the neural control of heart was intact $(1,2)$. In these dogs, the coronary artery perfusion pressure was then reduced by lowering the overflow column until the left ventricular end-diastolic pressure was approximately $15 \mathrm{~cm} \mathrm{H}_{2} \mathrm{O}$. Acetylstrophanthidin $(0.5 \mathrm{mg})$ was injected when the coronary sinus blood flow measurements were stable for $10 \mathrm{~min}$, and coronary blood flow determinations were again obtained at 1-min intervals for $30 \mathrm{~min}$. In three of these experiments, after a reflow period of $1 \mathrm{~h}$, acetylstrophanthidin data from a postischemic control period were also obtained. In four additional animals, the sequence was reversed and acetylstrophanthidin data were obtained under conditions of global ischemia first, and control data were obtained after a reflow period of $1 \mathrm{~h}$.

Five dogs with ischemic hearts received acetylstrophanthidin before and after alpha adrenergic receptor blockade with phenoxybenzamine $(5 \mathrm{mg} / \mathrm{kg})$. This dose of phenoxybenzamine abolished the coronary vasoconstrictor effects of methoxamine $(1.0 \mathrm{mg})$, which was given intravenously immediately before and $30 \mathrm{~min}$ after alpha adrenergic receptor blockade. In addition, phenoxybenzamine prevented the rise in systemic arterial pressure produced by methoxamine. Ischemia was produced in three animals without the administration of acetylstrophanthidin, and hemodynamic measurements were again obtained for 30 min.

In four animals, the effects of $1 \mathrm{mg}$ of i.v. digoxin on CVR were evaluated. Hemodynamic and coronary sinus blood flow measurements were made for $1 \mathrm{~h}$ after injection. Alpha adrenergic receptor blockade was achieved with phenoxybenzamine $(5 \mathrm{mg} / \mathrm{kg})$ before injection of digoxin in two additional dogs.

\section{RESULTS}

Fig. 3 demonstrates the effects of $0.5 \mathrm{mg}$ of i.v. acetylstrophanthidin on coronary vascular resistance and associated hemodynamics under nonischemic and ische-

\footnotetext{
${ }^{1}$ Abbreviation used in this paper: CVR, coronary vascular resistance.
}

mic conditions in one representative experiment. During the nonischemic control period (left panel of Fig. 3 ), the rise in coronary vascular resistance followed a smooth pattern and the associated hemodynamics were relatively stable. In contrast, during ischemia the increases in coronary vascular resistance were erratic, culminating in a sharp progressive increase in coronary resistance associated with a further elevation of left ventricular end-diastolic pressure (middle panel of Fig. 3 ). The coronary artery perfusion pressure, coronary blood flow, and left ventricular dp/dt were lower during ischemia and left ventricular end-diastolic pressure was higher, as compared with the values of these hemodynamics in the nonischemic period. The response of coronary vascular resistance to acetylstrophanthidin during the postischemic control period (right panel of Fig. 3) was similar to that of the pre-ischemic control period.

The mean coronary vascular resistance response to i.v. acetylstrophanthidin during the absence of ischemia from 13 dogs is presented in Fig. 4. The rise was significant $(P<0.01)$ from 1 through $24 \mathrm{~min}$ after acetylstrophanthidin administration. The mean control resistance in these nonischemic hearts was $1.2 \pm 0.1$ (SEM) $\mathrm{mm} \mathrm{Hg} / \mathrm{cm}^{3}$ per min. The mean rise in coronary vascular resistance after acetylstrophanthidin during ischemia in 15 dogs is shown in Fig. 5. The rise was significant $(P<0.01)$ from the 2nd through the 15th minute after acetylstrophanthidin. In 7 of these 15 dogs, a progressive terminal increase in coronary vascular resistance associated with an acute elevation of left ventricular end-diastolic pressure was observed (Table I). Ventricular fibrillation ensued in four of these seven dogs, and in three dogs coronary blood flow was deliberately increased to avoid ventricular fibrillation. The mean control resistance during ischemia before the injection of acetylstrophanthidin in the 15 dogs was $0.7 \pm 0.05 \mathrm{~mm} \mathrm{Hg} / \mathrm{cm}^{3}$ per min, significantly $(P<0.001)$ lower than that of the nonischemic control periods.

Table II summarizes the hemodynamic data from the 13 dogs during nonischemic control periods and 15 dogs during ischemia. The coronary vascular resistance, coronary blood flow, coronary artery perfusion pressure, and left ventricular $d \mathrm{p} / d \mathrm{t}$ were significantly lower $(P<0.001)$ and left ventricular end-diastolic pressure was significantly higher $(P<0.01)$ during ischemia. In addition, during ischemia, the hearts were in a negative lactate and potassium balance (Fig. 6). Particularly early during ischemia the coronary venous $\mathrm{PCO}_{2}$ was increased and the coronary venous $\mathrm{PO}_{2}$ and $\mathrm{pH}$ were decreased (Table III).

In the group without the progressive rise in coronary vascular resistance, the left ventricular end-diastolic pressure decreased from a mean of $16 \pm 1 \mathrm{~cm} \mathrm{H}_{2} \mathrm{O}$ to $11 \pm 1 \mathrm{~cm} \mathrm{H}_{2} \mathrm{O} \quad(P=0.05)$ and the left ventricular 


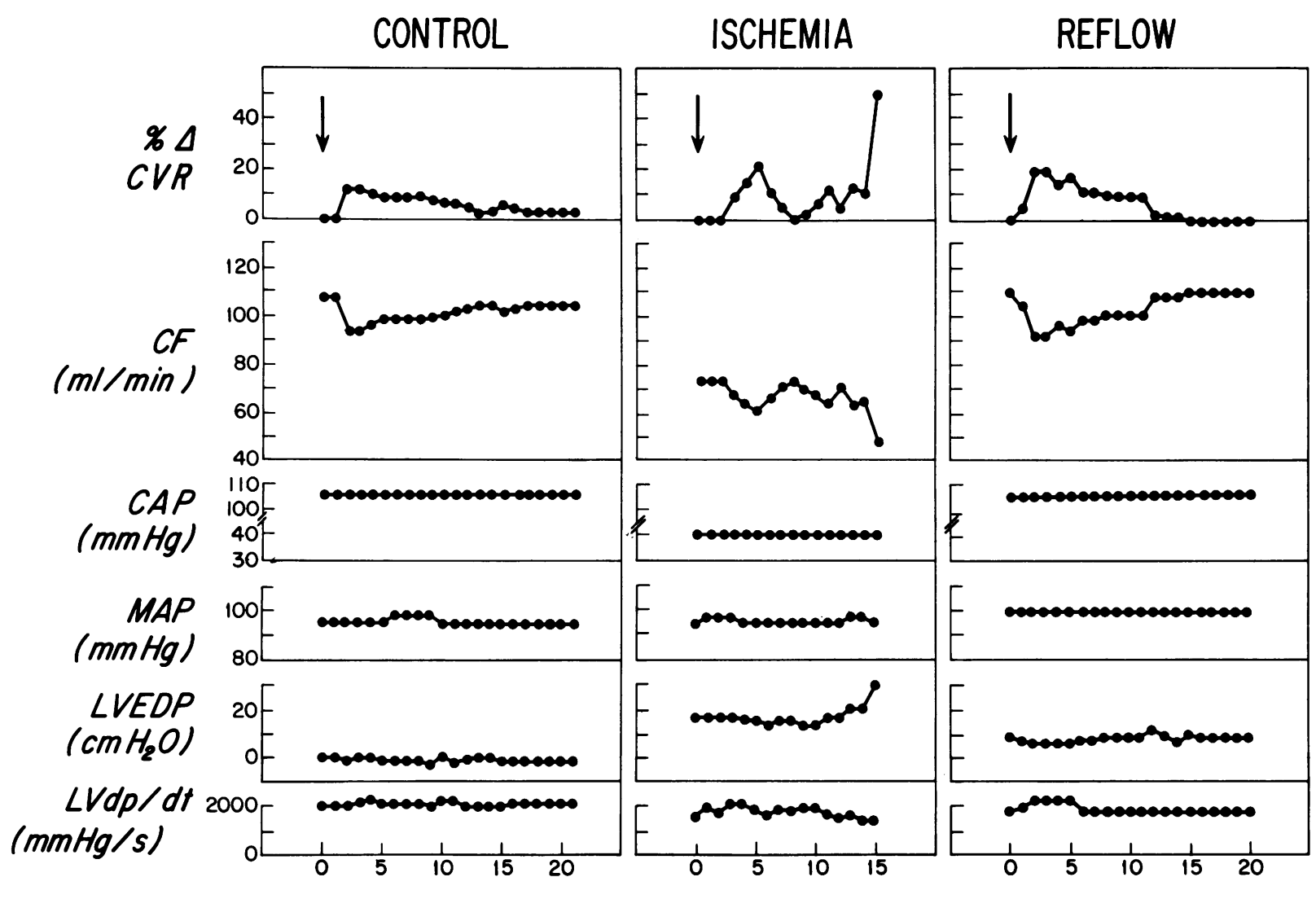

\section{MINUTES AFTER ACETYLSTROPHANTHIDIN $(0.5 \mathrm{mg})$}

FIGURE 3 Effects of i.v. acetylstrophanthidin on coronary resistance under nonischemic and ischemic conditions in the same heart. With ischemia, note the initial erratic changes in coronary vascular resistance terminating in a steep progressive increase. Also note the associated rise in left ventricular end-diastolic pressure. CVR, coronary vascular resistance; CF, coronary blood flow; CAP, coronary artery pressure; MAP, mean aortic pressure; LVEDP, left ventricular end-diastolic pressure; $\mathrm{LV} d \mathrm{p} / d \mathrm{t}$, the peak of the first derivative of left ventricular pressure.

$d \mathrm{p} / d \mathrm{t}$ increased from $1,800 \pm 100 \mathrm{~mm} \mathrm{Hg} / \mathrm{s}$ to 2,400 $\pm 100 \mathrm{~mm} \mathrm{Hg} / \mathrm{s}(P<0.05)$ at $20 \mathrm{~min}$ after the administration of acetylstrophanthidin. The left ventricular end-diastolic pressure data for each experiment

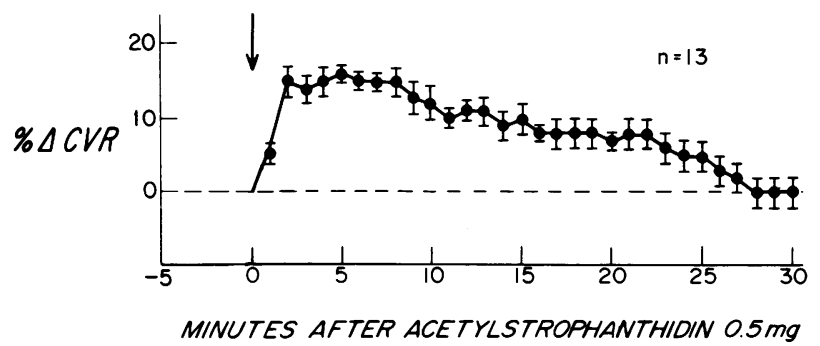

FIGURE 4 The effects of i.v. acetylstrophanthidin in the nonischemic hearts. Note the relatively smooth pattern of the increase of coronary vascular resistance (CVR). The increase in CVR was significant $(P<0.01)$ from minute 1 through minute 24. are in Table I. However, in the group with progressive increases in coronary resistance, the left ventricular end-diastolic pressure increased from $16 \pm 1$ $\mathrm{cm} \mathrm{H}_{2} \mathrm{O}$ to $24 \pm 2 \mathrm{~cm} \mathrm{H}_{2} \mathrm{O}(P<0.01)$ (Table I) and

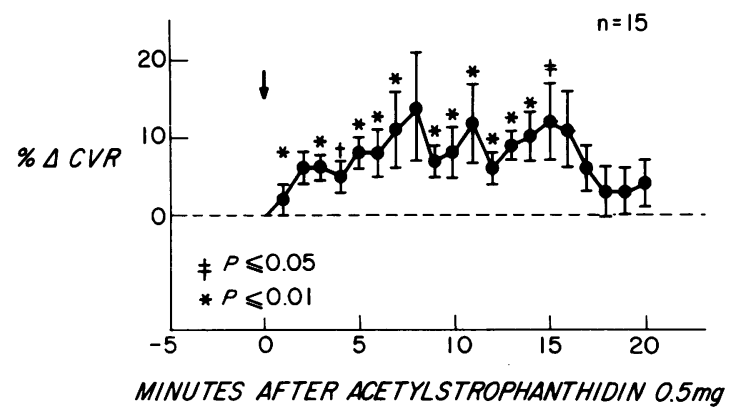

FIGURE 5 The effects of i.v. acetylstrophanthidin during ischemia. Note the significant increase in coronary vascular resistance in the presence of ischemia. 
TABLE I

Coronary Vascular Resistance and Left Ventricular End-Diastolic Pressure Data before and after i.v. Acetylstrophanthidin during Ischemia

\begin{tabular}{llllllll}
\hline Control & $3 \mathrm{~min}$ & $5 \mathrm{~min}$ & $7 \mathrm{~min}$ & $10 \mathrm{~min}$ & $12 \mathrm{~min}$ & $15 \mathrm{~min}$ \\
\hline
\end{tabular}

A. CVR* before and after i.v. acetylstrophanthidin, $\mathrm{mm} \mathrm{Hg} / \mathrm{cm}^{3} / \mathrm{min}$

Erratic CVR response

$\begin{array}{llllllll}1 . & 0.72 & 0.83 & 0.81 & 0.83 & 0.78 & 0.81 & 0.78 \\ 2 . & 0.78 & 0.85 & 0.83 & 0.81 & 0.83 & 0.78 & 0.85 \\ \text { 3. } & 0.73 & 0.73 & 0.77 & 0.77 & 0.83 & 0.83 & 0.86 \\ 4 . & 0.57 & 0.59 & 0.62 & 0.62 & 0.67 & 0.71 & 0.57 \\ 5 . & 0.94 & 0.96 & 0.92 & 0.94 & 0.96 & 0.98 & 1.04 \\ 6 . & 0.88 & 0.76 & 0.92 & 0.97 & 0.80 & 0.90 & 0.83 \\ 7 . & 0.54 & 0.54 & 0.55 & 0.60 & 0.52 & 0.52 & 0.52 \\ 8 . & 0.55 & 0.54 & 0.50 & 0.50 & 0.44 & 0.55 & 0.50\end{array}$

Progressive rise in CVR

$\begin{array}{rrrrrrrr}9 . & 0.90 & 1.05 & \ddagger & - & - & - & - \\ 10 . & 0.92 & 0.96 & 1.00 & 1.07 & 1.40 & \ddagger & - \\ 11 . & 1.25 & 1.47 & 1.51 & 2.17 & \ddagger & - & - \\ 12 . & 0.55 & 0.59 & 0.67 & 0.57 & 0.62 & 0.83 & \ddagger \\ 13 . & 0.70 & 0.70 & 0.64 & 0.81 & 1.1 & \ddagger & - \\ 14 . & 1.18 & 1.25 & 1.14 & 1.25 & 1.25 & 1.33 & \ddagger \\ 15 . & 0.89 & 0.94 & 1.01 & 1.01 & 0.98 & 1.01 & 1.35\end{array}$

B. LVEDP $\S$ before and after i.v. acetylstrophanthidin, $\mathrm{cm} \mathrm{H}_{2} \mathrm{O}$

Erratic CVR response

$\begin{array}{rrrrrrrr}1 . & 17 & 16 & 16 & 14 & 14 & 12 & 12 \\ 2 . & 15 & 14 & 13 & 13 & 12 & 10 & 10 \\ 3 . & 16 & 14 & 14 & 13 & 12 & 12 & 12 \\ 4 . & 14 & 13 & 12 & 12 & 11 & 8 & 8 \\ 5 . & 17 & 16 & 16 & 15 & 10 & 10 & 9 \\ 6 . & 14 & 13 & 12 & 10 & 10 & 10 & 10 \\ 7 . & 19 & 18 & 18 & 15 & 11 & 11 & 11 \\ 8 . & 15 & 16 & 14 & 13 & 11 & 10 & 10\end{array}$

Progressive rise in CVR

\begin{tabular}{rrrrrrrr}
9. & 16 & 16 & - & - & - & - & - \\
10. & 14 & 15 & 14 & 12 & 17 & - & - \\
11. & 18 & 18 & 17 & 22 & - & - & - \\
12. & 14 & 14 & 12 & 12 & 15 & 20 & - \\
13. & 15 & 12 & 12 & 15 & 30 & - & - \\
14. & 17 & 17 & 16 & 18 & 20 & 25 & - \\
15. & 16 & 15 & 13 & 13 & 14 & 24 & 40 \\
\hline
\end{tabular}

* CVR = coronary vascular resistance.

$\$$ Onset of ventricular fibrillation or restoration of normal coronary flow.

$\S$ LVEDP $=$ left ventricular end-diastolic pressure.

left ventricular $d \mathrm{p} / d \mathrm{t}$ decreased from $1,700 \pm 100 \mathrm{~mm}$ $\mathrm{Hg} / \mathrm{s}$ to $1,400 \pm 100 \mathrm{~mm} \mathrm{Hg} / \mathrm{s}(P<0.05)$ at the time of maximum rise in the coronary resistance.

In three dogs, prolonged ischemia without the administration of acetylstrophanthidin did not result in a progressive increase in coronary vascular resistance. The right and left panels of Fig. 7 illustrate the results from one animal. The changes in coronary vascular resistance without acetylstrophanthidin administration in these two panels were the greatest ob- served without the administration of this drug. In two of these three dogs, when coronary artery perfusion pressure was subsequently reduced further to increase the severity of the ischemia, there was an immediate increase in left ventricular end-diastolic pressure with an associated increase in coronary vascular resistance. The latter data illustrate that in this preparation, the progressive steep increase in coronary vascular resistance could be contributed to by the associated elevation of left ventricular end-diastolic pressure. 

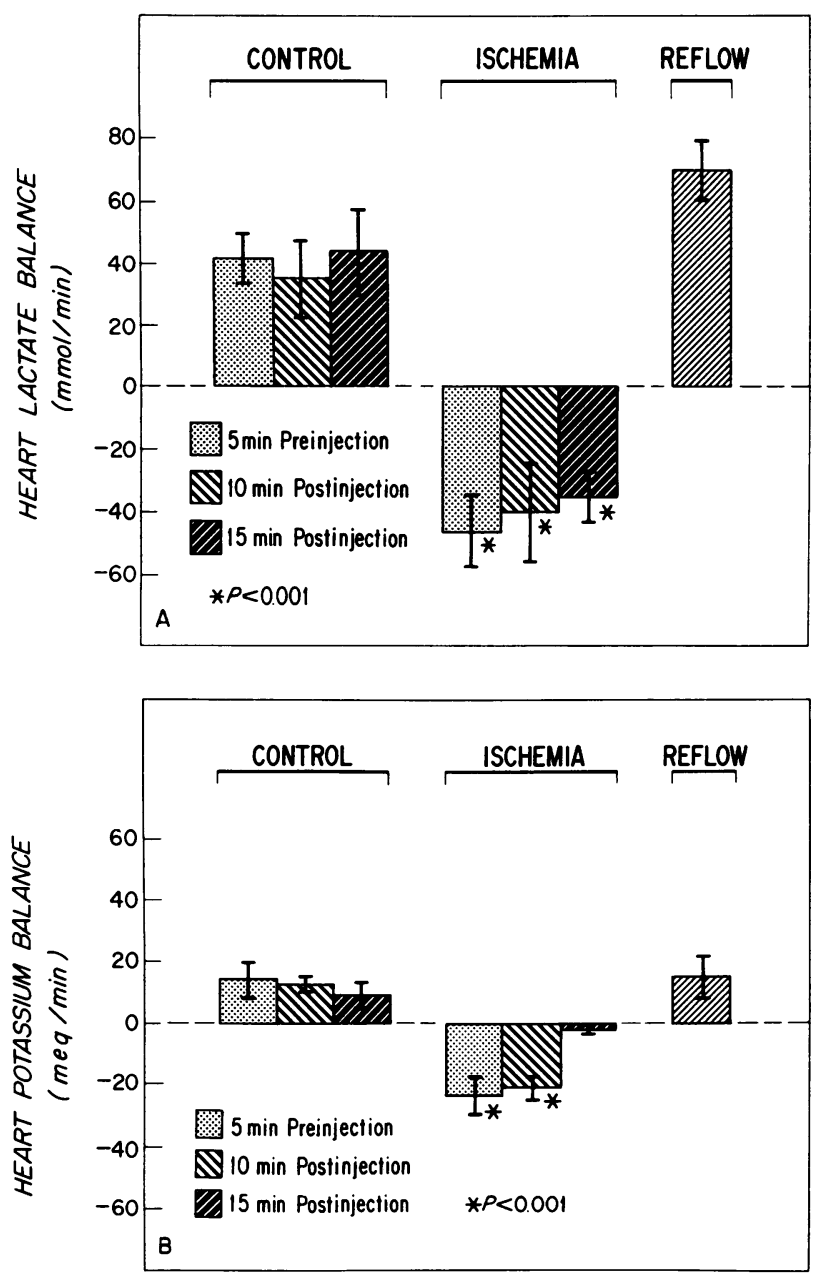

Figure 6 (A) Reversal of the lactate balance of the heart during ischemia. (B) Reversal of the potassium balance of the heart during ischemia.

In five dogs, prior alpha adrenergic receptor blockade with phenoxybenzamine during ischemia abolished the increases in coronary vascular resistance after acetylstrophanthidin. Fig. 8 is illustrative: the bottom panel shows the greatest change in coronary vascular resistance observed after alpha receptor blockade and acetylstrophanthidin. The difference in response of coronary vascular resistance was due to alpha adrenergic receptor blockade and not to tachyphylaxis, because in two dogs, second injections of acetylstrophanthidin during ischemia, in the absence of alpha receptor blockade, resulted in erratic increases in coronary vascular resistance.

The effects of i.v. digoxin (1.0 mg) on coronary vascular resistance under conditions of low coronary perfusion were evaluated in four dogs. The top four panels of Fig. 9 demonstrate that increases in coronary vascular resistance were observed in all four animals. In two dogs, increases in coronary vascular resistance culminated in ventricular fibrillation. In the fourth panel from the top, the data revealed erratic increases in coronary vascular resistance without ventricular fibrillation. In the second panel of Fig. 9, the response of coronary vascular resistance was smooth and rather sustained, resembling that seen when digoxin is injected under nonischemic conditions $(1,2)$. It is of interest that the left ventricular end-diastolic pressure in this $\operatorname{dog}$ was $9 \mathrm{~cm} \mathrm{H}_{2} \mathrm{O}$, the lowest value occurring in any of the hearts in this present study in which

TABLE II

Associated Hemodynamic Data before and after i.v. Acetylstrophanthidin

\begin{tabular}{|c|c|c|c|c|c|c|c|c|c|}
\hline & $-10 \mathrm{~min}$ & $-5 \min$ & $0 \mathrm{~min}$ & $3 \mathrm{~min}$ & $5 \mathrm{~min}$ & $10 \mathrm{~min}$ & $15 \mathrm{~min}$ & $20 \mathrm{~min}$ & $30 \mathrm{~min}$ \\
\hline \multicolumn{10}{|c|}{ A. Nonischemic hemodynamics before and after i.v. acetylstrophanthidin } \\
\hline CVR, ${ }^{*} \mathrm{~mm} \mathrm{Hg} / \mathrm{cm}^{3}$ per $\min$ & $1.18 \pm 0.09$ & $1.18 \pm 0.09$ & $1.18 \pm 0.10$ & $1.35 \pm 0.10 \ddagger$ & $1.38 \pm 0.10 \ddagger$ & $1.34 \pm 0.10 \ddagger$ & $1.30 \pm 0.11 \ddagger$ & $1.26 \pm 0.10 \rrbracket$ & $1.18 \pm 0.11$ \\
\hline $\mathrm{CF}, \S \mathrm{ml} / \mathrm{min}$ & $84 \pm 6$ & $84 \pm 6$ & $84 \pm 6$ & $73 \pm 5 t$ & $72 \pm 5 \ddagger$ & $74 \pm 6 !$ & $77 \pm 6$ & $79 \pm 6$ & $83 \pm 4$ \\
\hline CAP," $m m \mathbf{H g}$ & $99 \pm 2$ & $99 \pm 2$ & $99 \pm 2$ & $100 \pm 1$ & $99 \pm 1$ & $99 \pm 1$ & $99 \pm 1$ & $99 \pm 1$ & $99 \pm 1$ \\
\hline MAP, $\mathrm{mm} \mathrm{Hg}$ & $87 \pm 3$ & $87 \pm 3$ & $87 \pm 3$ & $88 \pm 3$ & $87 \pm 4$ & $87 \pm 2$ & $87 \pm 3$ & $87 \pm 3$ & $87 \pm 3$ \\
\hline LVEDP, ${ }^{* *} \mathrm{~cm} \mathrm{H}_{2} \mathrm{O}$ & $6 \pm 1$ & $6 \pm 1$ & $6 \pm 1$ & $6 \pm 1$ & $6 \pm 1$ & $6 \pm 1$ & $5 \pm 1$ & $5 \pm 1$ & $5 \pm 1$ \\
\hline $\mathrm{LV} d \mathrm{p} / d \mathrm{t}, \sharp \mathrm{mm} H \mathrm{Hg} / \mathrm{s}$ & $2,600 \pm 200$ & $2,600 \pm 200$ & $2,600 \pm 200$ & $2,700 \pm 150$ & $2,700 \pm 150$ & $2,700 \pm 150$ & $2,700 \pm 200$ & $2,700 \pm 200$ & $2,700 \pm 200$ \\
\hline
\end{tabular}

\begin{tabular}{|c|c|c|c|c|c|}
\hline $\mathrm{CVR},{ }^{*} \mathrm{~mm} \mathrm{Hg} / \mathrm{cm}^{3}$ per $\min$ & $0.72 \pm 0.05$ & $0.72 \pm 0.05$ & $0.72 \pm 0.05$ & $0.76 \pm 0.05 t$ & $0.79 \pm 0.05 t$ \\
\hline $\mathrm{CF}, \$ \mathrm{ml} / \mathrm{min}$ & $46 \pm 2$ & $46 \pm 3$ & $46 \pm 3$ & $44 \pm 3 \rrbracket$ & $43 \pm 3 \rrbracket$ \\
\hline $\mathrm{CAP}, " m m \mathrm{Hg}$ & $40 \pm 2$ & $40 \pm 2$ & $40 \pm 2$ & $40 \pm 3$ & $40 \pm 3$ \\
\hline MAP, $\mathbb{m m} \mathbf{H g}$ & $80 \pm 2$ & $80 \pm 2$ & $80 \pm 2$ & $80 \pm 2$ & $80 \pm 2$ \\
\hline LVEDP, ${ }^{* *} \mathrm{~cm} \mathrm{H}_{2} \mathrm{O}$ & $16 \pm 1$ & $16 \pm 1$ & $16 \pm 1$ & $15 \pm 1$ & $14 \pm 1$ \\
\hline $\begin{array}{l}\mathrm{LV} d \mathrm{p} / d \mathrm{t}, 1 \mathrm{t} \mathrm{mm} \mathrm{Hg} / \mathrm{s} \\
\quad n=15\end{array}$ & $1,700 \pm 100$ & $1,700 \pm 100$ & $1,700 \pm 100$ & $1,800 \pm 100$ & $1,800 \pm 100$ \\
\hline $\begin{array}{l}\text { Values are } \pm \text { SEM. } \\
\text { * CVR }=\text { coronary vascular } \\
\text { † } P<0.05 \text {. } \\
\$ C F=\text { coronary blood flo }\end{array}$ & tance. & \multicolumn{4}{|c|}{$\begin{array}{l}\text { "CAP = coronary artery pressure. } \\
\text { I MAP = mean aortic pressure. } \\
\text { ** LVEDP = left ventricular end-di }\end{array}$} \\
\hline
\end{tabular}


TABLE III

Associated Arterial and Coronary Venous $\mathrm{PO}_{2}, \mathrm{PCO}_{2}$, and $p \mathrm{H}$ before and after i.v. Acetylstrophanthidin

\begin{tabular}{|c|c|c|c|c|c|c|c|c|c|c|}
\hline & \multicolumn{4}{|c|}{ No ischemia } & \multicolumn{4}{|c|}{ Ischemia } & & \\
\hline & \multicolumn{2}{|c|}{$-5 \min$} & \multicolumn{2}{|c|}{$10 \mathrm{~min}$} & \multicolumn{2}{|c|}{$-5 \min$} & \multicolumn{2}{|c|}{$10 \mathrm{~min}$} & \multicolumn{2}{|c|}{ Reflow } \\
\hline & $\mathbf{A}$ & v & $\mathbf{A}$ & V & $\mathbf{A}$ & V & $\mathbf{A}$ & V & $\mathbf{A}$ & $\mathrm{V}$ \\
\hline $\mathrm{Po}_{2}, m m \mathrm{Hg}$ & $400 \pm 52$ & $44 \pm 3$ & $360 \pm 61$ & $42 \pm 3$ & $390 \pm 66$ & $31 \pm 4^{*}$ & $344 \pm 62$ & $31 \pm 2$ & $302 \pm 54$ & $49 \pm 4$ \\
\hline $\mathrm{PCO}_{2}, \mathrm{~mm} \mathrm{Hg}$ & $28 \pm 2$ & $36 \pm 3$ & $27 \pm 2$ & $36 \pm 3$ & $30 \pm 2$ & $60 \pm 6^{*}$ & $28 \pm 2$ & $54 \pm 4$ & $35 \pm 4$ & $44 \pm 4$ \\
\hline $\mathrm{pH}$ & $7.48 \pm 0.03$ & $7.42 \pm 0.02$ & $7.44 \pm 0.01$ & $7.41 \pm 0.01$ & $7.41 \pm 0.02$ & $7.27 \pm 0.03^{*}$ & $7.39 \pm 0.02$ & $7.24 \pm 0.02$ & $7.41 \pm 0.01$ & $7.37 \pm 0.01$ \\
\hline
\end{tabular}

$n=10$; values are \pm SEM.

${ }^{*} P \leq 0.05$.

coronary blood flow was deliberately decreased. The associated hemodynamic data are given in Table IV. There was little change in left ventricular end-diastolic pressure and left ventricular $d \mathrm{p} / d \mathrm{t}$ in the two dogs with erratic increases in coronary resistance. In the two dogs with progressive increases in coronary vascular resistance, there were accompanying increases in left ventricular end-diastolic pressure.

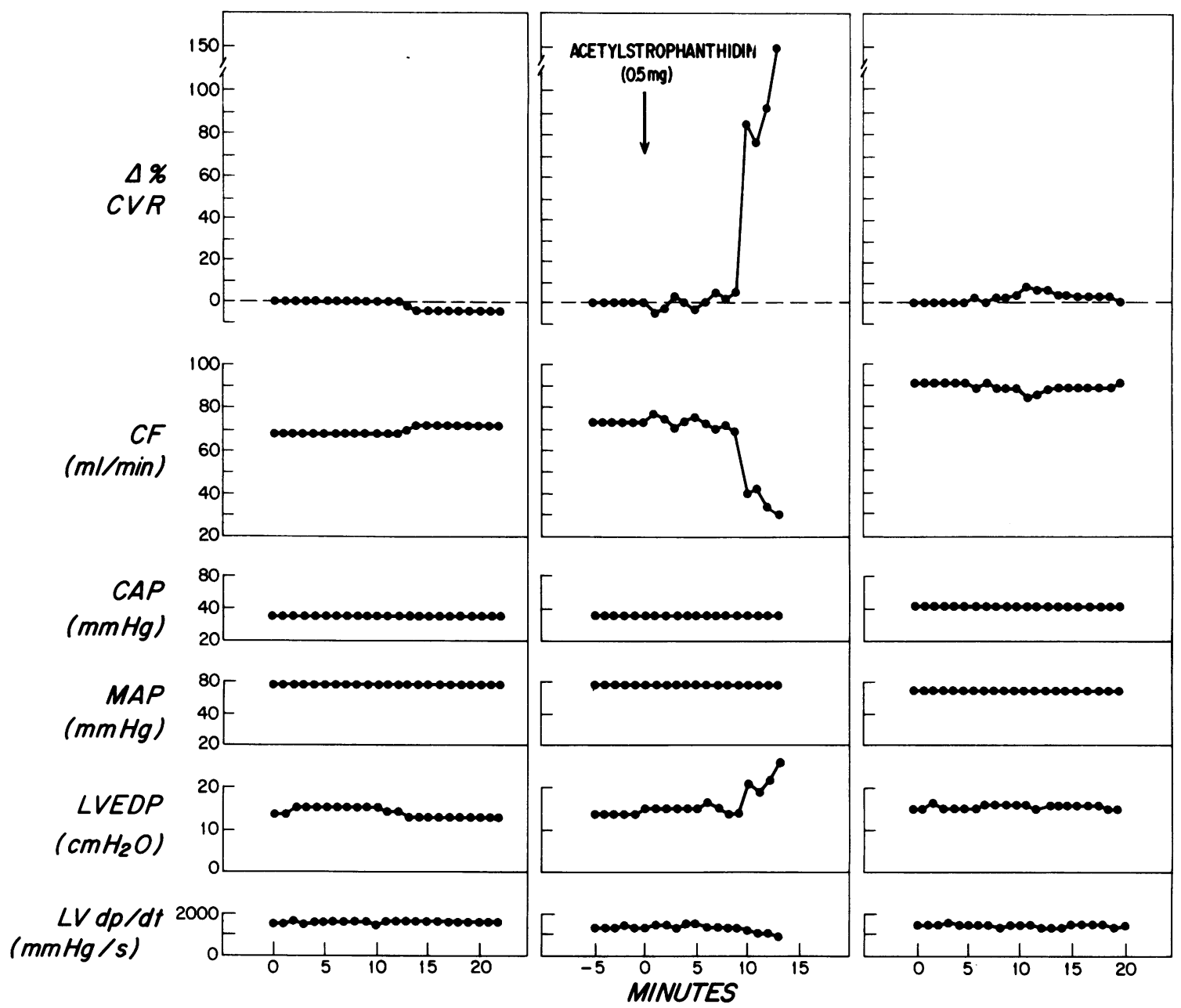

FIGURE 7 The effects of ischemia alone and ischemia with acetylstrophanthidin on coronary vascular resistance in one animal. In the center panel there is a progressive increase in coronary resistance after i.v. acetylstrophanthidin. The left and right panels show no change in coronary resistance during ischemia without the administration of acetylstrophanthidin. Abbreviations as in Fig. 3. 


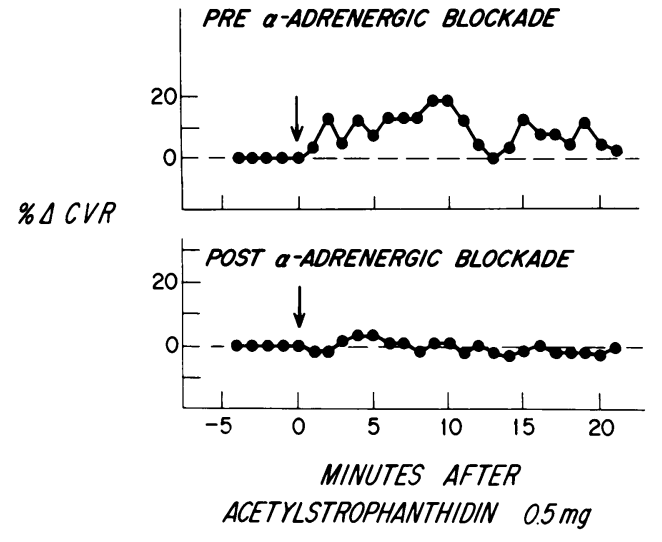

FIGURE 8 The effect of i.v. acetylstrophanthidin on coronary vascular resistance during ischemia before and after alpha adrenergic receptor blockade. Note that erratic rise in CVR is no longer present after the alpha blockade.

In two additional dogs, prior alpha adrenergic receptor blockade during ischemia abolished the increases in coronary resistance produced by digoxin (lower two panels of Fig. 9). Stability of the left ventricular end-diastolic pressure and left ventricular $d \mathrm{p} / d \mathrm{t}$ were noted in these two dogs after the injection of digoxin.

\section{DISCUSSION}

The data demonstrate that the rapid i.v. administration of digitalis results in vasoconstriction of the coronary circulation during acute global ischemia in the canine heart. The mechanism of this vasoconstriction is neurogenic and appears mediated through stimulation of alpha adrenergic receptors. The increase in coronary vascular resistance during ischemia can be associated with rapid deterioration of left ventricular function.

The coronary vasoconstriction which occurs during ischemia after digitalis administration appears to be the result of alpha adrenergic receptor stimulation and not some other property of ischemia. The evidence for this is twofold. First, during control ischemia experiments in which digitalis was withheld, minimal to no vasoconstriction was observed. Second, the coronary vasoconstriction with digitalis was abolished by pharmacologic blockade of alpha adrenergic receptors. Thus, the mechanism of the neurogenic vasoconstrictor response during acute global ischemia of the heart is similar to that in nonischemic skeletal muscle (11) and in the nonischemic coronary circulation $(1,2)$.

It has been demonstrated in paced and nonpaced beating hearts and in fibrillating hearts that stimulation of the stellate ganglia and the intracoronary administration of norepinephrine both produce an initial coronary vasoconstriction followed by vasodilation (12). The delayed vasodilation was due to enhanced metabolic activity associated with increases in left ventricular $d \mathrm{p} / d \mathrm{t}$, heart rate, and systemic arterial pressure. Blockade of this latter myocardial response with beta adrenergic receptor antagonist reversed the vasodilator response to a sustained vasoconstriction (13). Also, in skeletal muscle Remensnyder et al. (14) demonstrated that neurogenic vasoconstriction could be completely abolished by exercise. Similarly, Donald et al. (15) showed that during exercise in dogs the hind limb blood flow increased in direct relation to the severity of exercise both in presence of an intact lumbar sympathetic chain and after lumbar sympathetectomy. However, stimulation of the lumbar sympathetic chain in the exercising hind limb - produced a significant reduction in blood flow. Similarly, in the present study the neurogenic coronary vasoconstriction produced by digitalis persisted despite various metabolic alterations associated with is-
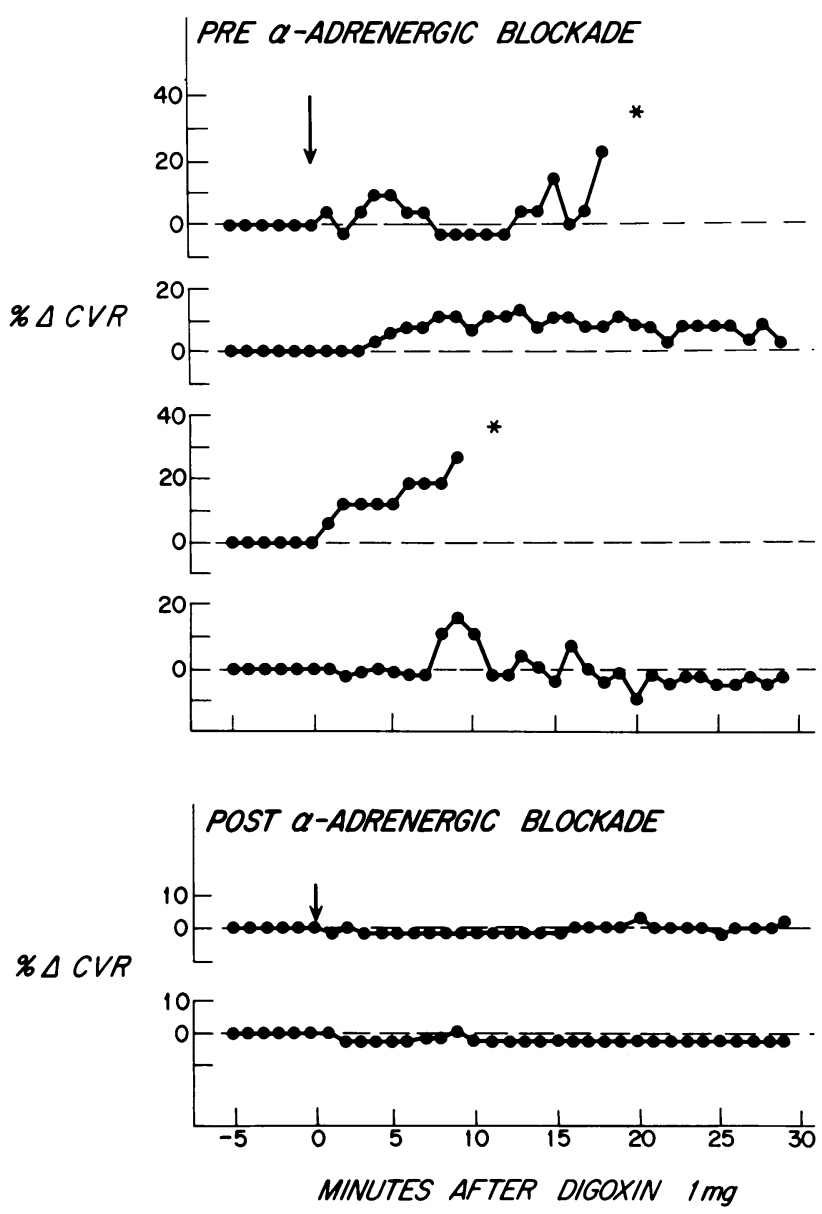

FIGURE 9 The effect of i.v. digoxin on coronary vascular resistance during ischemia before and after alpha adrenergic receptor blockade. 
TABLE IV

Ischemic Hemodynamics before and after i.v. Digoxin

\begin{tabular}{|c|c|c|c|c|c|c|c|}
\hline & Time & $\% \Delta \mathrm{CVR}^{*}$ & 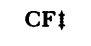 & CAP $\$$ & MAP" & LVEDPA & $\mathbf{L V} d \mathrm{p} / d d^{* *}$ \\
\hline & $\min$ & & $\mathrm{ml} / \mathrm{min}$ & $m m \mathrm{Hg}$ & $m m \mathrm{Hg}$ & $\mathrm{Cm} \mathrm{H} \mathrm{H}_{2} \mathrm{O}$ & $m m \mathrm{Hg} / \mathrm{s}$ \\
\hline \multirow[t]{4}{*}{ No. 1} & Control & 0 & 52 & 45 & 75 & 13 & 1,900 \\
\hline & 5 & 9 & 48 & 45 & 75 & 13 & 1,900 \\
\hline & 10 & -3 & 54 & 45 & 75 & 14 & 1,900 \\
\hline & 15 & +15 & 46 & 45 & 75 & 16 & 1,800 \\
\hline \multirow[t]{6}{*}{ No. 2} & Control & 0 & 62 & 40 & 75 & 9 & 2,000 \\
\hline & 5 & +6 & 59 & 40 & 75 & 10 & 2,000 \\
\hline & 10 & +11 & 54 & 40 & 75 & 10 & 1,900 \\
\hline & 15 & +11 & 54 & 40 & 75 & 11 & 2,000 \\
\hline & 30 & +3 & 60 & 40 & 75 & 11 & 2,000 \\
\hline & 50 & +3 & 60 & 40 & 75 & 11 & 1,900 \\
\hline \multirow[t]{3}{*}{ No. 3} & Control & 0 & 38 & 45 & 75 & 12 & 2,000 \\
\hline & 5 & +12 & 34 & 45 & 75 & 15 & 1,900 \\
\hline & 9 & +27 & 30 & 45 & 75 & 28 & 1,600 \\
\hline \multirow[t]{6}{*}{ No. 4} & Control & 0 & 57 & 45 & 75 & 12 & 2,000 \\
\hline & 5 & -2 & 59 & 45 & 75 & 12 & 2,000 \\
\hline & 10 & +16 & 50 & 45 & 75 & 11 & 2,100 \\
\hline & 15 & -2 & 62 & 45 & 75 & 12 & 2,000 \\
\hline & 30 & -2 & 62 & 45 & 75 & 12 & 1,900 \\
\hline & 50 & -2 & 62 & 45 & 75 & 12 & 1,900 \\
\hline
\end{tabular}

$* \% \Delta \mathrm{CVR}$, percent change in coronary vascular resistance.

$\ddagger \mathrm{CF}$, coronary blood flow.

\$CAP, coronary artery pressure.

"MAP, mean aortic pressure.

I LVEDP, left ventricular end-diastolic pressure.

${ }^{* *} \mathrm{LV} d \mathrm{p} / d \mathrm{t}$, left ventricular peak $d \mathrm{P} / d \mathrm{t}$.

chemia. These metabolic alterations would be expected to have produced net vasodilation $(3,4)$.

In approximately $50 \%$ of the hearts under conditions of ischemia, there was a progressive rise in coronary vascular resistance which was associated with rapid deterioration of left ventricular function. This study does not give information regarding this difference in response, since the base-line hemodynamics were similar in the hearts which deteriorated and those which did not deteriorate. It is likely that in the first group the vasoconstriction produced by digitalis increased the severity of ischemia, which in turn resulted in an elevation of left ventricular end-diastolic pressure. However, the progressive increase in coronary vascular resistance and ventricular fibrillation may be concomitant effects of digitalis, as this drug has important effects on the electrical properties of cardiac muscle.

The present data from the ischemic hearts and our previous data from nonischemic hearts $(1,2)$ demonstrate that increases in coronary vascular resistance occur soon after the i.v. administration of digoxin in the absence of documented positive inotropic effects of the drug. The effect mediated through alpha adrener- gic receptor stimulation occurs well before the expected inotropic effect of digoxin. The finding of a lack of improvement in left ventricular filling pressure in the hour after the acute administration of digitalis is consonant with several clinical series $(5,6,9)$. Indeed there are reports in the literature of acute elevations of left ventricular filling pressure $(7,8)$ shortly after i.v. digoxin. Furthermore, Balcon et al. (5) have demonstrated in 11 patients with recent myocardial infarctions and clinical evidence of depressed left ventricular function that within that hour after acute digitalization, there was a consistent fall in cardiac output. This was not associated with an increase in systemic blood pressure. In one patient from this series, an attack of angina was precipitated $8 \mathrm{~min}$ after i.v. digoxin. Thus, it is possible that the i.v. administration of digitalis glycosides may, in the period immediately after acute administration, produce only detrimental effects and that these detrimental effects may be importantly related to an increase in coronary vascular resistance.

A recent experimental study (16) has documented that shortly after the administration of i.v. digoxin to the nonfailing heart, there is an increase in the extent 
and severity of regional myocardial ischemia. This has been presumed to be due entirely to an increase in inotropy with an associated increase in myocardial oxygen demand. In our studies, the lack of change in left ventricular end-diastolic pressure and left ventricular $d \mathrm{p} / d \mathrm{t}$ with the administration of digoxin suggests the possibility that this drug may increase ischemia solely secondary to neurogenic coronary vasoconstriction. However, one should be cautious in extrapolating the results of the present study in which the ischemia was global and the degree of ischemia which was produced was limited by the overall function of the heart to the clinical situation; it is possible that the metabolic consequences of severe regional ischemia combined with left ventricular failure may be sufficient to prevent the neurogenic coronary vasoconstrictor effects of digitalis. Nevertheless, the present study establishes that the acute administration of digitalis is capable of producing neurogenic coronary vasoconstriction under conditions of ischemia and elevated ventricular end-diastolic pressure.

\section{ACKNOWLEDGMENTS}

We gratefully acknowledge the helpful technical assistance of Mr. Luis Guerrero, Mr. Michael Bissanti, Mr. Michael Wiechowski, Miss Mary McGovern, and Mr. Alvin Denenberg. We are also grateful for the capable secretarial assistance of Miss Lois Sturm.

This paper was supported, in part, by U. S. Public Health Service grants 1 RO1 HL 18657, 5P50 HL 17665-02, and HL 06664.

\section{REFERENCES}

1. Hamlin, N. P., J. T. Willerson, H. Garan, and W. J. Powell, Jr. 1974. The neurogenic vasocontrictor effect of digitalis on coronary vascular resistance. J. Clin. Invest. 53: 288-296.

2. Garan, H., T. W. Smith, and W. J. Powell, Jr. 1974. The central nervous system as a site of action for the coronary vasoconstrictor effect of digoxin. J. Clin. Invest. 54: $1365-1372$.
3. Daugherty, R. M., Jr., J. B. Scott, J. M. Dabney, and F. J. Haddy. 1967. Local effects of $\mathrm{O}_{2}, \mathrm{CO}_{2}$ on limb, renal and coronary vascular resistances. Am. J. Physiol. 213(5): 1102-1110.

4. Haddy, F. J., and J. B. Scott. 1968. Metabolically linked vasoactive chemicals in local regulation of blood flow. Physiol. Rev. 48: 688-706.

5. Balcon, R., H. Hoy, and E. Sowton. 1968. Haemodynamic effects of rapid digitalization following acute myocardial infarction. Br. Heart J. 30: 373-376.

6. Hodges, M., G. C. Friesinger, R. C. K. Riggins, and G. R. Dagenais. 1972. Effects of intravenously administered digoxin on mild left ventricular failure in acute myocardial infarction in man. Am. J. Cardiol. 29: 749-756.

7. Cohn, J. N., F. E. Tristani, and I. M. Khatri. 1969. Cardiac and peripheral vascular effects of digitalis in clinical cardiogenic shock. Am. Heart J. 78: 318-330.

8. Lipp, H., P. Denes, M. Gambetta, and L. Resnekov. 1973. Hemodynamic response to acute intravenous digoxin in patients with recent myocardial infarction and coronary insufficiency with and without heart failure. Chest. 63: 862-867.

9. Forrester, J., W. Bezdek, K. Chatterjee, P. Levin, W. W. Parmley, and H. J. C. Swan. 1972. Hemodynamic effects of digitalis in acute myocardial infarction. Ann. Intern. Med. 76: 863-864.

10. Gregg, D. E., and L. C. Fisher. 1963. Blood supply to the heart. Handb. Physiol. 2(Sect. 2): 1517-1584.

11. Stark, J. J., C. A. Sanders, and W. J. Powell, Jr. 1972. Neurally mediated and direct effects of acetylstrophanthidin on canine skeletal muscle vascular resistance. Circ. res. 30: 274-282.

12. Rubio, R., and R. M. Berne. 1975. Regulation of coronary blood flow. Prog. Cardiovasc. Dis. 18(2): 105-122.

13. Feigl, E. O. 1975. Control of myocardial oxygen tension by sympathetic coronary vasoconstriction in the dog. Circ. Res. 37: 88-95.

14. Remensnyder, J. P., J. H. Mitchell, and S. J. Sarnoff. 1962. Functional sympatholysis during muscular activity: observations on influence of carotid sinus on oxygen uptake. Circ. Res. 11: 370-380.

15. Donald, D. E., D. J. Rowlands, and D. Ferguson. 1970. Similarity of blood flow in the normal and the sympathectomised dog hind limb during graded exercise. Circ. Res. 26: 185-199.

16. Maroko, P. R., J. K. Kjekshus, B. E. Sobel, T. Wanabe, J. W. Covell, J. Ross, Jr., and E. Braunwald. 1971. Factors influencing infarct size following experimental coronary artery occlusion. Circulation. 43: 67-82. 